\title{
Sealing Ability of MTA vs Portland Cement in the Repair of Furcal Perforations of Primary Molars: A Dye Extraction Leakage Model—An In Vitro Study
}

\author{
Nagireddy V Reddy ${ }^{1}$, Pythari Srujana ${ }^{2}$, Velagala Daneswari ${ }^{3}$, Harivinder R Konyala ${ }^{4}$, Ajay R Mareddy ${ }^{5}$, Noorjahan Mohammad ${ }^{6}$
}

\begin{abstract}
Aim: The purpose of this present study is to compare the ability of MTA and Portland cement to seal furcal perforations in extracted primary molars using the dye extraction leakage model.

Materials and methods: Sixty primary molars were selected and randomly divided into four groups after access openings and furcal perforations were created in the pulp chamber floor. Group I $(n=20)$ in which perforations were repaired with MTA (ProRoot MTA, MTA-Angelus), group II $(n=20)$ in which perforations were repaired with the Portland cement, group III $(n=10)$ in which perforations were left unsealed (positive control), and group IV $(n=10)$ without perforations (negative control). All samples were subjected to $1 \%$ of basic fuchsin dye challenge followed by dye extraction with $65 \mathrm{wt} \%$ of nitric acid. Samples were analyzed using the automatic microplate spectrophotometer $545 \mathrm{~nm}$ and the readings were statistically analyzed.

Results: There was no statistically significant difference in the microleakage between MTA and Portland cement repair groups.

Conclusion: Portland cement provides an effective seal for primary teeth furcal perforations and can be considered a more economic substitute for MTA as a repair material enhancing the prognosis of perforated primary teeth that would otherwise be extracted.

Keywords: Dye extraction, MTA, Perforation, Portland cement.

International Journal of Clinical Pediatric Dentistry (2019): 10.5005/jp-journals-10005-1597
\end{abstract}

\section{INTRODUCTION}

Preservation of an intact primary dentition until the eruption of the permanent successors is very important in maintaining the arch form. In the case of a primary tooth that has suffered pulpal insult because of trauma or dental caries, retention of the pulpally involved tooth helps in preserving the arch space if the normal function can be restored and resolution of the pathologic process can be achieved. ${ }^{1}$ Researchers have attempted to combine the most effective pulp therapy techniques with the most reliable materials. ${ }^{2}$

Accidental perforations of pulpal floor during endodontic treatment affect the prognosis of the treatment. ${ }^{3}$ Ingle, in the Washington study which is the most valid study in the field of investigating success and failure of endodontic treatments in 1961, reported that $9.61 \%$ of failures were due to perforations which occur when trying to find the orifice of the canals in the floor of the pulp chamber. ${ }^{4}$ Kvinnsland et al. in their study found that perforations occurred in all tooth groups but were most common in the maxilla accounting for $73 \%$ of the cases reported. In the mandibular arch, the first molar was the tooth most frequently perforated; during root canal treatment, the reason for perforation was attempting to negotiate calcified canals (42\%)..$^{5}$

A variety of materials have been suggested for the nonsurgical repair of furcation perforation including amalgam, intermediate restorative material (IRM), gutta-percha, dentine chips, $\mathrm{Ca}(\mathrm{OH})_{2}$, Cavit, tricalcium phosphate, hydroxyapatite, glass ionomer cement, and Super ethoxy benzoic acid (EBA). However, these materials require a dry field and they do not promote new tissue formation. ${ }^{6}$ Moisture, bleeding, unconventional accessibility, and a bottomless cavity, however, make repair of the perforation difficult which will eventually have a great impact on the prognosis of perforated teeth. ${ }^{4}$ \begin{tabular}{l}
\hline${ }^{1-6}$ Department of Paediatric and Preventive Dentistry, Mamata Dental \\
College, Khammam, Telangana, India
\end{tabular}

Corresponding Author: Nagireddy V Reddy, Department of Paediatric and Preventive Dentistry, Mamata Dental College, Khammam, Telangana, India, Phone: +91 8519971174, e-mail: pedobud@gmail.com

How to cite this article: Reddy NV, Srujana P, et al. Sealing Ability of MTA vs Portland Cement in the Repair of Furcal Perforations of Primary Molars: A Dye Extraction Leakage Model-An In Vitro Study. Int J Clin Pediatr Dent 2019;12(2):83-87.

Source of support: Cotti E, Mereu M, et al. Regenerative treatment of an immature, traumatized tooth with apical periodontitis: report of a case. J Endod 2008;34:611-616; Huang GT, Sonoyama W, et al. The hidden treasure in apical papilla: the potential role in pulp/dentin regeneration and bioroot engineering. J Endod 2008;34:645-651.

Conflict of interest: None

In recent decades, a new material known as MTA has been introduced by Torabinejad in 1993, which is capable of creating a thorough seal between root canals and external dental surfaces. ${ }^{7}$ It is a hydrophilic cement that can set in the presence of water. ${ }^{8}$ There are several studies that have demonstrated its excellent sealing ability. However, the MTA has certain drawbacks, i.e., presence of toxic elements, difficulty in handling, long setting time, and high material cost. MTA is a derivative of Portland cement which contains the same principal chemical elements as MTA except for bismuth oxide. ${ }^{6}$ Therefore, the possibility of using Portland cement as a less expensive alternative to MTA in dental practice is to be considered. ${ }^{8}$

In this view, the purpose of this present study is to compare the ability of MTA and Portland cement to seal furcal perforations in extracted primary molars using the dye extraction leakage model.

() The Author(s). 2019 Open Access This article is distributed under the terms of the Creative Commons Attribution 4.0 International License (https://creativecommons. org/licenses/by-nc/4.0/), which permits unrestricted use, distribution, and non-commercial reproduction in any medium, provided you give appropriate credit to the original author(s) and the source, provide a link to the Creative Commons license, and indicate if changes were made. The Creative Commons Public Domain Dedication waiver (http://creativecommons.org/publicdomain/zero/1.0/) applies to the data made available in this article, unless otherwise stated. 


\section{Materials and Methods}

Freshly extracted 60 primary molars were collected from the Department of Pediatric and Preventive Dentistry and kept in 5\% of sodium hypochlorite (Vishal Dentocare Pvt. Ltd, Ahmedabad, Gujarat, India) for 30 minutes. They were then cleaned of any debris and washed under tap water and kept in normal saline (Abaris Healthcare Pvt. Ltd, India) until the next step. ${ }^{4}$

\section{Teeth Preparation}

The primary molars were amputated $3 \mathrm{~mm}$ below the furcation area using a tapered diamond stone (Dentsply, India Pvt. Ltd) (Fig. 1). The endodontic access cavity was prepared in every molar with a round bur \#2 (Dentsply, India Pvt. Ltd) and the root canal orifices were located. The canal orifices and the apical end of each root were etched with $37 \%$ of phosphoric acid gel (Prime Dental Products Pvt. Ltd, Thane) for 30 seconds, and then the single bond adhesive system (3M ESPE Dental Products, St. Paul, MN, USA) was applied in 2 consecutive coats and photopolymerized for 10 seconds with a LED source. A resin composite Z100 (3M ESPE Dental Products, St. Paul, MN, USA) was then used to fill the root canal orifices as well as the apical end of the root and was then photopolymerized for 40 seconds (Fig. 2). Every molar was

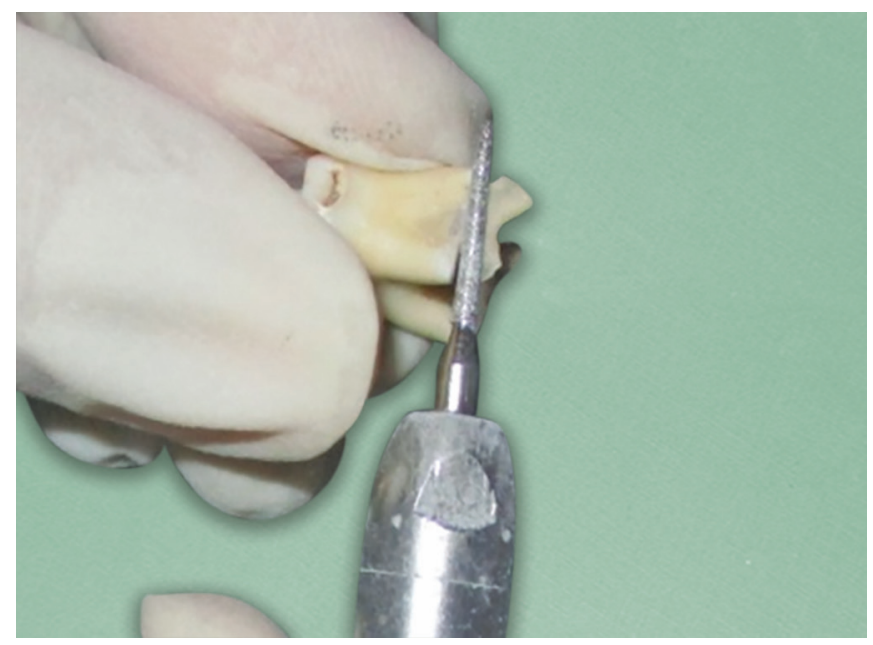

Fig. 1: Amputation of teeth

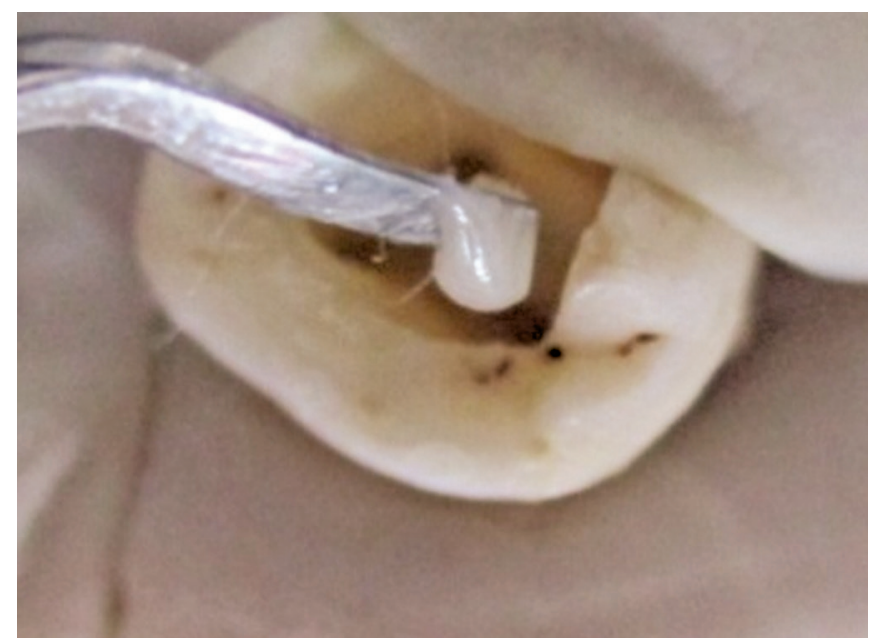

Fig. 2: Closing the orifices with composite covered completely including cavity walls and pulpal floor with two successive layers of clear nail varnish in an attempt to increase the marginal seal and to prevent bacterial leakage through lateral canals or other discontinuities in the cementum. ${ }^{6,10}$

\section{Creation of Furcal Perforations}

A silicone impression material (Zeta plus intro kit, Italy) was mixed according to the manufacturer instructions to provide a matrix that simulated the bony socket. The primary molars were placed into the unset silicone impression material and then removed after polymerization. Artificial perforations were created in the center of the floor of the pulp chamber of each primary tooth with round bur \#2 in a low-speed handpiece (Nsk Pana Air Japan) along an axis parallel to the long axis of the tooth, while holding the tooth in the hands (Fig. 3), the width of the perforations was equal to the diameter of the perforating bur, proceeded to $2 \mathrm{~mm}$ of the file \#80 length. ${ }^{4}$

\section{Repair Procedures and Materials}

Then the teeth were divided into four groups:

Group I: 20 molars in which the perforations were repaired with MTA (Maillefer, Dentsply, Switzerland).

Group II: 20 molars in which the perforations were repaired with Portland cement (Ultra Tech Cement Limited, Jodhpur, Rajasthan). Group III: 10 molars in which perforations were left unsealed (positive control).

Group IV: 10 molars without perforations (negative control).

In group I, the perforation site was repaired with ProRoot MTA (Maillefer, Dentsply, Switzerland), which was mixed according to the instructions from the manufacturer, placed with an amalgam carrier and compacted with a hand plugger.

In group II, the perforation site was repaired with Portland cement (Ultra Tech Cement Limited, Jodhpur, Rajasthan). The powder was sterilized using dry heat (YORCO, York Scientific Industries Pvt. Ltd, Chennai) at $170^{\circ} \mathrm{C}$ for 1 hour. ${ }^{11}$ One gram of the powder was then mixed with the sterile distilled water to produce a homogenous paste, placed with an amalgam carrier and compacted with a hand plugger (Mani, Prime Dental Products Pvt. Ltd, Japan).

The moist cotton pellet was placed over the repair material to simulate clinical environment at the perforation site ${ }^{12}$ and the teeth were kept in an incubator (YORCO, York Scientific Industries Pvt. Ltd, Chennai) at $37^{\circ} \mathrm{C}$ in $100 \%$ humidity for 24 hours to allow the materials to set. ${ }^{13}$

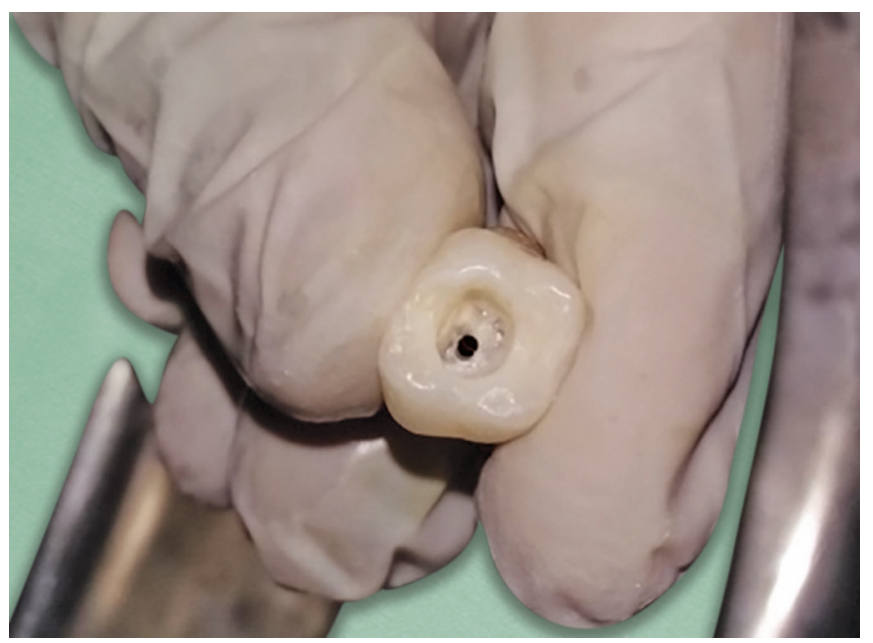

Fig. 3: Creation of perforation 


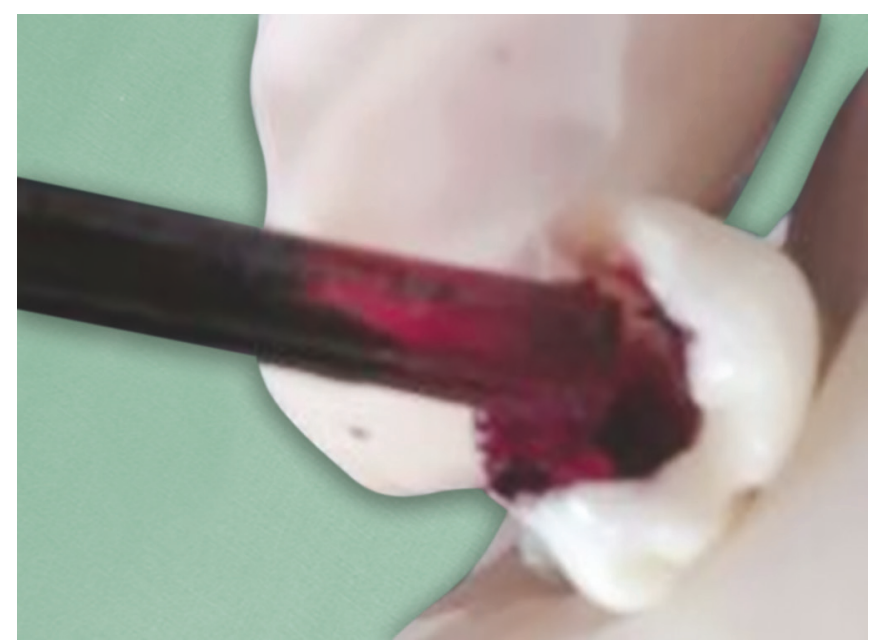

Fig. 4: Placing basic fuchsin dye

The basic fuchsin dye of $1 \%$ was applied inside the access cavity of all primary teeth for 24 hours (Fig. 4). Then, the teeth were placed under running water for 30 minutes to remove all residues of the basic fuchsin dye. The varnish was removed with parker blade \#15 (Glassvan, Niraj industries Pvt. Ltd, India)

\section{Microleakage Measurement}

The teeth were placed in vials containing $1 \mathrm{~mL}$ of concentrated (65 wt\%) nitric acid (MERK Specialties, Pvt., Mumbai) until complete dissolution (Fig. 5). Vials were centrifuged at 9,000 rpm for 7 minutes (Fig. 6). Two hundred microliters of the supernatant from each sample was transferred to a 96-well plate. The sample absorbance was read by an automatic microplate spectrophotometer (StatFax-2100, Awareness Technology, Inc., 1935 S.W. Martin Hwy, Palm City, FL 34990, USA) at 545 nm using concentrated nitric acid as a blank.

\section{Statistical Analysis}

Results obtained were subjected to statistical analysis using the Statistical Package for Social Sciences software, version 24.0. Analysis of one-way variance test (ANOVA) was used to compare the mean of the different groups and Tukey's post hoc test was used for pair-wise comparisons between the groups. The significance level was set at $p \leq 0.05$.

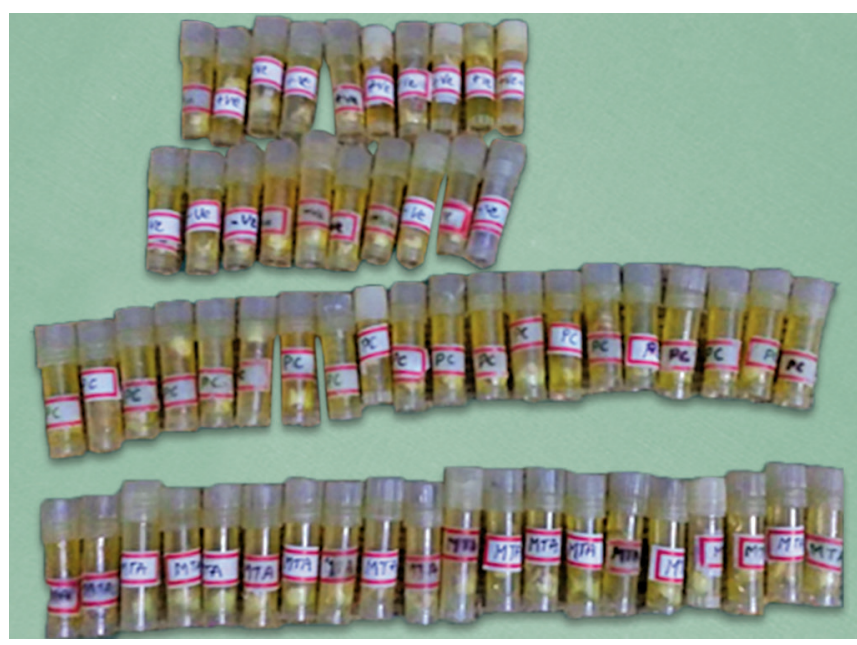

Fig. 5: Teeth placed in the vials containing nitric acid

\section{Results}

The data were presented as mean and standard deviation values in Table 1 and Figure 7. Mean leakage values in the four groups showed a statistically significant difference between the groups, i.e., 0.0001 . Group III showed the highest dye absorbance $(0.653 \pm 0.221)$ followed by groups II $(0.265 \pm 0.142)$ and I $(0.264 \pm 0.234)$ and group IV $(0.063 \pm$ 0.008), Table 2 shows Tukey's post hoc test values for pair-wise comparisons between the groups, with leakage as a dependent variable used in the procedure, there was no statistically significant difference between the dye absorbance values in the Portland cement repair group and the MTA cement repair group and values of both groups were significantly higher than the negative control group.

\section{Discussion}

Furcal repair in primary teeth has become more essential than extraction, to prolong the longevity of the tooth. ${ }^{3}$ Bryan et al. reviewed the etiology, diagnosis, prognosis, and material selection of nonsurgical repair of furcation perforation and stated that the furcal perforations as such had a bad prognosis and, thus, should be sealed immediately with biocompatible and sealable material. ${ }^{14}$

However, the divergent outcomes have demonstrated that so far no ideal sealing material has been achieved, i.e., a material that

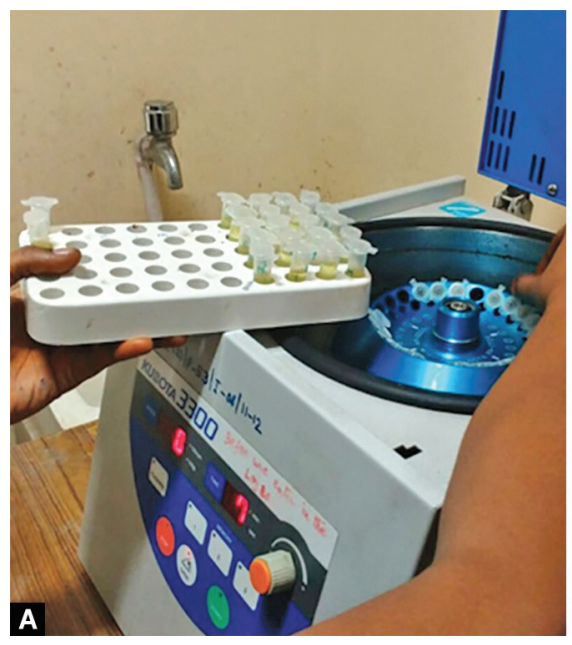

Figs $6 \mathrm{~A}$ and $\mathrm{B}$ : Centrifuging the vials at $9,000 \mathrm{rpm}$ for $7 \mathrm{~min}$

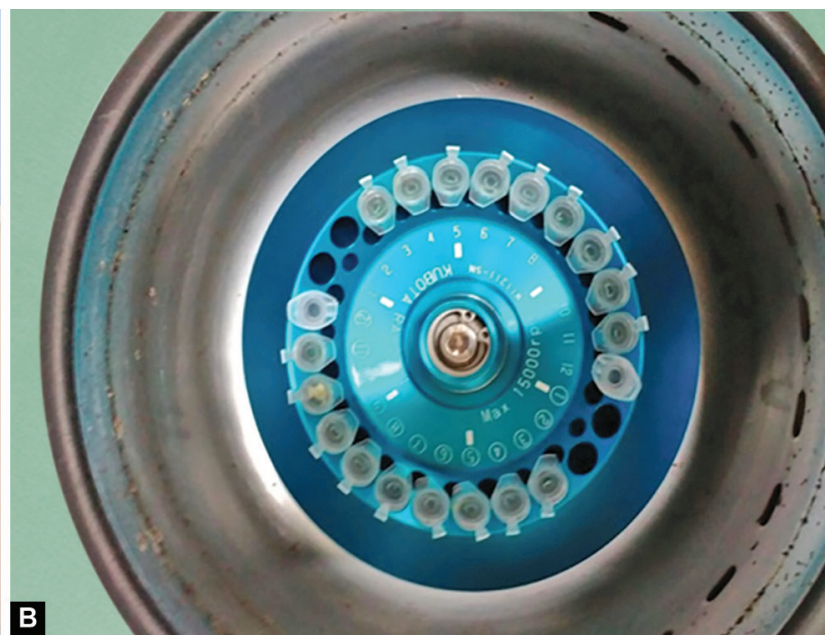

B 
Table 1: Mean leakage values in the four groups

\begin{tabular}{lllll}
\hline Group & N & Mean & $\begin{array}{l}\text { Std. } \\
\text { deviation }\end{array}$ & p value \\
\hline I & 20 & 0.264 & 0.234 & $<0.0001$ \\
II & 20 & 0.265 & 0.142 & \\
III & 10 & 0.653 & 0.221 & \\
IV & 10 & 0.063 & 0.008 & \\
\hline
\end{tabular}

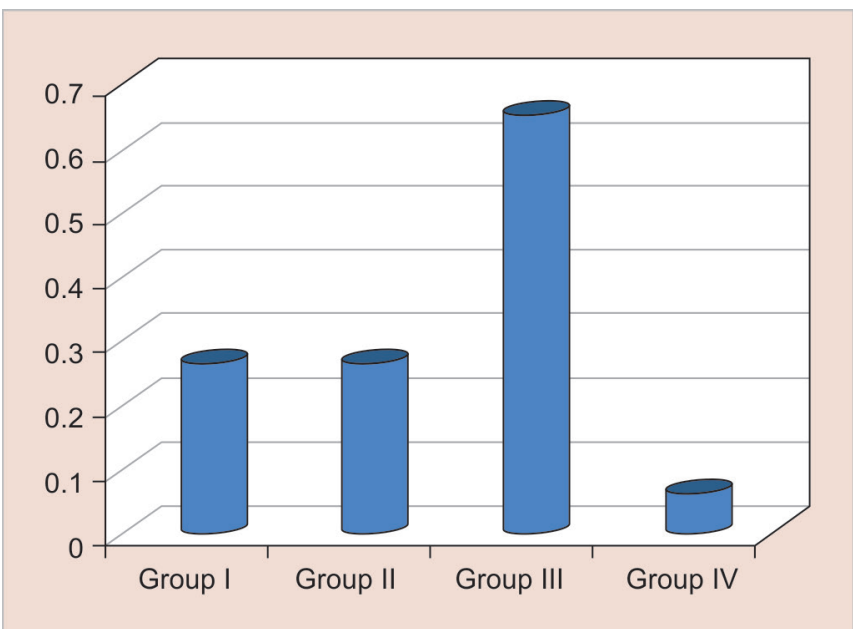

Fig. 7: Mean leakage values in the four groups

Table 2: Pair-wise comparisons between the groups

\begin{tabular}{|c|c|c|c|c|}
\hline Pair & Groups & $\begin{array}{l}\text { Mean } \\
\text { difference }\end{array}$ & Std. error & $p$ value \\
\hline \multirow[t]{3}{*}{ I } & 1 & -0.0003 & 0.0577 & 1.000 \\
\hline & III & -0.3899 & 0.0707 & 0.000 \\
\hline & IV & 0.2014 & 0.0707 & 0.030 \\
\hline \multirow[t]{3}{*}{ II } & I & 0.0003 & 0.0577 & 1.000 \\
\hline & III & -0.3887 & 0.0707 & 0.000 \\
\hline & IV & 0.2016 & 0.0707 & 0.030 \\
\hline
\end{tabular}

may provide optimal sealing, easy manipulation, biocompatibility, and ability of induction of osteogenesis and cementogenesis. ${ }^{15}$ The favorable chemical and biological properties of MTA have changed this scenario. ${ }^{16}$ But MTA has certain drawbacks such as long setting time, poor handling, and relatively high price. During the past few years, it has been confirmed that MTA is Portland cement (PC) plus bismuthoxide. ${ }^{3}$ MTA consists of $75 \mathrm{wt} \%$ of PC, $20 \%$ of bismuth oxide, and $5 \mathrm{wt} \%$ of calcium sulfate as a setting modifier. ${ }^{17}$ Biological evaluation of MTA, PC, or $\mathrm{Ca}(\mathrm{OH})_{2}$ showed that the mechanisms of action of the materials are similar. ${ }^{18}$ This has generated scientific interest in the evaluation of PC as a low-cost alternative to MTA. ${ }^{10}$

In this study, we have used the dye extraction technique to compare the sealing ability. The dye-penetration technique has long been used in endodontics because of its ease of performance and difficulty of other available techniques. However, it has several drawbacks including the smaller molecular size of the dye molecules than bacteria, which do not measure the actual volume absorbed by the sample but merely measure the deepest point reached by the dye. Despite these drawbacks, Torabinejad et al. stated that a material that is able to prevent the penetration of small molecules (dye) should be able to prevent larger substances like bacteria and their by-products. ${ }^{19}$ In the dye extraction technique, the teeth are dissolved in acids that release all the dye from the interface and the optical density of the solution is measured by a spectrophotometer. According to Camps and Pashley, there was no correlation among dye penetration, fluid filtration, and dye extraction techniques which determine microleakage. The fluid infiltration technique gave similar results to those of dye extraction, but the dye extraction technique presents advantage over the fluid filtration method, because the filtration values tend to diminish over time as water penetrates all the irregularities until a plateau is reached. ${ }^{20}$ Based on this, the dye-extraction method seems to be a reliable technique, it takes into account all the absorbed dye by the samples and similar technique was also used in other studies., 9,19,21,22

The compatibility of the dye materials and the tested materials can adversely affect the microleakage results. The use of methylene blue in marginal sealing studies has been questioned, due to its incompatibility with alkaline substances which may induce discoloration of the dye. Since calcium oxide is one of the components found in MTA, when calcium oxide is mixed with water, it results in the formation of calcium hydroxide, with a subsequent increase in $\mathrm{pH}$ as demonstrated by Duarte et al. Thus, discoloration of the surfaces stained by methylene blue may occur. Therefore, the basic fuchsin solution was more appropriate for evaluating the sealing ability in this study. ${ }^{9}$

The results of the present study revealed that the positive control group showed the highest dye absorbance $(0.653 \pm 0.221)$ followed by the Portland cement group $(0.265 \pm 0.142)$ and the MTA group $(0.264 \pm$ $0.234)$ and the negative control group $(0.063 \pm 0.008)$. No significant difference between the dye absorbance values of the MTA repair group and the Portland cement repair group was seen. However, the dye absorbance values of both groups were significantly higher than the negative control group. Negative control had low dye absorbance (0.063) close to that of blank (nitric acid), which showed an absorbance of 0.044 . This small difference can be attributed to the yellowish color of teeth, whereas the blank is colorless. The positive control group had the highest dye absorbance (0.653) of all groups denoting the accuracy of the technique. This was in agreement with the studies conducted by De-Deus et al., Charrier et al., Holland et al., Wucherpfenning and Green, Estrela et al., and Holland et al. 6,10,19,23

\section{Conclusion}

Within the limits of the present study, the following conclusions can be drawn:

- No significant difference between the dye absorbance values of the MTA repair group and the PC repair group.

- It could be concluded that PC provides an effective seal for primary teeth furcal perforations and can be considered a more economic substitute for MTA as a repair material enhancing the prognosis of perforated primary teeth that would otherwise be extracted.

\section{References}

1. Barr ES, Flaitz CM, et al. A retrospective radiographic evaluation of primary molar pulpectomies. Pediatr Dent 1991;13(1):4-9.

2. Kofman $\mathrm{SH}$, Schneider-Friedman C, et al. Retrospective clinical study of pulp treatment with ferric sulfate and formocresol. Acta Stomatol Croat 2006;40(2):107-115.

3. Samuel A, Asokan S, et al. Evaluation of sealing ability of Biodentine ${ }^{\mathrm{TM}}$ and MTA in primary molars using scanning electron microscope: a randomized controlled in vitro trial. Contemp Clin Dent 2016;7(3): 322-325. DOI: 10.4103/0976-237X.188547.

4. Ahangari Z, Karami M. Evaluation of the sealing ability of Amalgam, MTA, Portland Cement and Coltozol in the repair of furcal perforations. Iran Endod J 2006;1(2):60-64. 
5. McCabe PS. Avoiding perforations in endodontics. J Ir Dent Assoc 2006;52:139-148.

6. De-Deus G, Petrucelli V, et al. MTA vs portland cement as repair material for furcal perforations: a laboratory study using a polymicrobial leakage model. J Endod 2006;39(4):293-298. DOI: 10.1111/j.1365-2591.2006. 01096.x.

7. Shahi S, Rahini S, et al. Sealing ability of MTA and Portland cement for furcal perforation repair: a protein leakage study. J Oral Sci 2009;51(4):601-606. DOI: 10.2334/josnusd.51.601.

8. Mangala MG, Chandra SM, et al. To evaluate the biocompatibility of the Indian portland cement with potential for use in dentistry: an animal study. J Conserv Dent 2015;18(6):440-444. DOI: 10.4103/09720707.168800.

9. Tawil SBE, Dokky NAE, et al. Sealing ability of MTA vs Portland cement in the repair of furcal perforations of primary molars: a dye extraction leakage model. J Am Sci 2011;7(12):1037-1043.

10. De-Deus G, Reis $C$, et al. The ability of Portland cement, MTA, and MTA Bio to prevent through-and-through fluid movement in repaired furcal perforations. J Endod 2007;33(11):1374-1377. DOI: 10.1016/ j.joen.2007.07.024.

11. Simon JH, Oglesby SW, et al. Sterilization of Portland Cement Endod, 8540 Sepulveda Boulevard, Suite 1117, Los Angeles, California 90045. USC School of Dentistry microbiology lab.

12. Daoudi MF, Saunders WP. In vitro evaluation of furcal perforation repair using mineral trioxide aggregate or resin modified glass lonomer cement with and without the use of the operating microscope. J Endod 2002;28(7):512-515. DOI: 10.1097/00004770-20020700000006.

13. Kaya S, Ayaz SG, et al. Comparing MTA and Ketac Molar easymix for furcation perforation repair using a volumetric method. Int Dent Res 2011;1(1):13-17. DOI: 10.5577/intdentres.2011.vol1.no1.3.
14. Khodary HM, Farsi DJ, et al. Sealing ability of four calcium containing cements used for repairing furcal perforations in primary teeth. J Contemp Clin Dent 2015;16(9):733-739.

15. Broon NJ, Braman TECM, et al. Healing of root perforations treated with MTA and Portland cement. J Appl Oral Sci 2006;14(5):305-311. DOI: 10.1590/S1678-77572006000500002.

16. Neto JDS, Schnaider TB, et al. Portland cement with additives in the repair of furcation perforations in dogs. Acta Cir Bras 2012;27(11): 809-812. DOI: 10.1590/S0102-86502012001100011.

17. Hwang $\mathrm{YC}$, Lee $\mathrm{SH}$, et al. Chemical composition, radiopacity, and biocompatibility of portland cement with bismuth oxide. Oral Surg Oral Med Oral Pathol Oral Radiol Endod 2009;107(3):96-102. DOI: 10.1016/j.tripleo.2008.11.015.

18. Borges $\mathrm{AH}$, Bandeca $\mathrm{MC}$, et al. Portland cement use in dental root perforations. A long term follow up. Case Rep Dent 2014. DOI: $10.1155 / 2014 / 637693$

19. Hashem AA, Hassanien EE. ProRoot MTA, MTA-Angelus and IRM used to repair large furcation perforations: sealability study. J Endod 2008;34(1):59-61. DOI: 10.1016/j.joen.2007.09.007.

20. Verissimo DM, Vale MS. Methodologies for assessment of apical and coronal leakage of endodontic filling materials: a critical review. J Oral Sci 2006;48(3):93-98. DOI: 10.2334/josnusd.48.93.

21. Reddy DSR, Kommineni N, et al. Comparative evaluation of sealability of different root canal perforation repair materials by using a dyeextraction leakage method_An in vitro study. Ind. J Dent Sci 2013;5(4): $1-4$.

22. Hashem AA, Hassanien EE. Pro Root MTA, MTA-Angelus and IRM used to repair large furcation perforations: sealability study. J Endod 2008;34(1):59-61. DOI: 10.1016/j.joen.2007.09.007.

23. Charrier M, Medioni E. Microleakage of three filling materials for furcation perforation. Eur Cell Mater 2007;13(1):9. 